\title{
ACTIVE HAGEMAN FACTOR: A PLASMA LYSOKINASE OF THE HUMAN FIBRINOLYTIC SYSTEM *
}

\author{
BY SOTIRIOS G. IATRIDIS AND JOHN H. FERGUSON
}

(From the Department of Physiology, School of Medicine, University of North Carolina, Chapel Hill, N. C.)

(Submitted for publication November 13, 1961 ; accepted February 15, 1962)

Normal human and animal plasmas contain a precursor globulin, plasminogen, which can be converted to plasmin, the active fibrinolytic enzyme, by a variety of activator agents.

The general term "activator" has been used so widely that it would often seem inadvisable to attempt to replace it by a more specific one. Nevertheless, this term is inappropriate for the specific characterization of agents which convert plasminogen into plasmin. We therefore propose the specific term plasminoplastin for those agents which produce plasmin by "direct" action on human and animal plasminogen. It is thus implied that agents like streptokinase, which convert plasminogen to plasmin "indirectly" (in two steps) should not be termed plasminoplastins, but rather lysokinases (1).

Human plasminogen can be converted to plasmin either by the direct action of tissue, plasma, or urine plasminoplastins, or by the indirect action of the lysokinases (e.g., streptokinase). The plasma factor, which reacts with a lysokinase to form the plasma (or endogenous) plasminoplastin, can be termed proplasminoplastin (proactivator). The latter factor has not yet been isolated and characterized; therefore, much controversy surrounds its nature and identity.

Fibrinolytic activity can also be developed "spontaneously," that is, by a mechanism occurring in the blood itself, as compared with the activity induced by the addition of known plasminoplastins or lysokinases.

Many attempts have been made to elucidate the mechanism of the "spontaneous" activation of the fibrinolytic system, but the problem has not yet been entirely solved. From a theoretical point of view, there appear to be at least two possible mechanisms. The first is the release of plasminoplastin

* Aided by Grant $\mathrm{H}-1510-\mathrm{C}_{8}$ from the NIH Division of Research Grants and Fellowships, USPHS. from the tissues into the circulation; the second is an increase in the plasma plasminoplastin by some unidentified "activator" mechanism.

Regarding the first possibility, the presence of large amounts of plasminoplastin in many tissues (2-4) suggested that local liberation of tissue plasminoplastin from injured tissue is important in effecting resolution of fibrin deposits locally in tissues and, to a lesser degree, in the vascular bed (1). Extending these observations, Kwaan, Lo and McFadzean (5-7) presented evidence to suggest that the walls of the vessels contain a cholinergic effector mechanism, which, when stimulated (e.g., ischemia due to vasoconstriction of vasa vasorum ; local injection of epinephrine, acetylcholine, histamine, or serotonin), responds by releasing plasminoplastin into the circulation. Astrup and Permin (4) have reported that some tissues, in addition to the large amounts of plasminoplastin, contain measurable quantities of a substance with a lysokinase effect. Müllertz (8) extended this concept by proposing that the spontaneous increase of the fibrinolytic activity in blood (which is actually an increase of plasma plasminoplastin) is associated with increased permeability of the vascular endothelium and release of a tissue component (lysokinase) which combines with proplasminoplastin in blood to form plasminoplastin.

Regarding the second possibility, which is here further explored, some evidence for a serum lysokinase was presented by Lewis and Ferguson (9). They prepared from normal dog serum two fractions (fraction $\mathrm{K}$ and proplasmin), which remained inactive when stored separately, but developed strong fibrinolytic activity after incubation of a mixture of the two for several weeks at $5^{\circ} \mathrm{C}$. They concluded that fraction $\mathrm{K}$ (serum fibrinolysokinase) was responsible for the spontaneous appearance of plasmin in whole serum treated with chloroform. Presumably, this serum frac- 
tion $\mathrm{K}$ was either lysokinase (1) or plasminoplastin, in the activation of which a serum lysokinase was involved.

Further evidence for the existence of a plasma factor with activity of a lysokinase was given recently $(10,11)$. It was found that normal euglobulin suspension incubated at $37^{\circ} \mathrm{C}$ showed an increase of plasminoplastin activity, while Hageman-deficient euglobulin suspension did not increase its activity under the same experimental conditions. Hence, it was suggested that Hageman factor may participate in the activation of the proplasminoplastin.

The present study was undertaken in order to investigate further the role of Hageman factor in the generation of the plasma plasminoplastin. The results indicate 1) that the factor which is developed during the incubation of normal euglobulin suspension is a plasminoplastin; 2) that "active Hageman factor" acts like lysokinase on the proplasminoplastin to form plasminoplastin; and 3 ) that human plasmin, devoid of Hagemanlike activity, is ineffectual in the generation of plasma plasminoplastin.

\section{MATERIALS AND METHODS}

Normal human intact plasma. Using a silicone technique, blood from the arm vein of normal donors was collected in 0.1 vol of 3.2 per cent sodium citrate. This was centrifuged at $4^{\circ} \mathrm{C}$ for 30 minutes at $3,000 \mathrm{rpm}$ and the upper two-thirds, transferred to a siliconized tube, were considered as "intact platelet-poor" plasma (12).

Hageman-deficient plasma. Blood from a well studied patient with Hageman trait (L. C.) $(13,14)$ was collected and centrifuged as for the normal.

Chicken intact plasma. Using the silicone technique, jugular vein blood was collected, citrated, and centrifuged as for human plasma.

Bovine fibrinogen was a 2 per cent stock solution of Armour's bovine Fraction I (fibrinogen) in borate buffer, $\mathrm{pH}$ 7.6, from which dilutions in the same buffer were made as required. In using this fibrinogen to prepare "unheated fibrin plates" (see below), its content of plasminogen was usually satisfactory for the purpose of testing plasminoplastins.

Thrombin (bovine) was supplied through the courtesy of Dr. J. T. Correll (Upjohn Co.) ; potency according to manufacturer. The fibrin, which formed with the above fibrinogen and this thrombin, did not lyse in the controls.

Surface factor (SF) was prepared by a modification of Waaler's procedure (15). Normal citrated plasma was adsorbed with concentrated $\mathrm{Al}(\mathrm{OH})_{3}(0.1 \mathrm{ml}$ per $\mathrm{ml})^{1}$ for 5 minutes at $37^{\circ} \mathrm{C}$. This plasma is deficient in prothrombin (Factor II), proconvertin (Factor VII), plasma thromboplastin component (PTC; Factor IX) and Stuart (Factor $\mathrm{X}$ ). The adsorption does not decrease the amount of Hageman factor (XII) appreciably, but it does considerably decrease the amount of plasma thromboplastin antecedent (PTA; Factor XI) (16). The adsorbed plasma was exposed to kaolin $(10 \mathrm{mg}$ per $\mathrm{ml}$ ) in a Lusteroid tube for 10 minutes at room temperature. After centrifuging at 3,000 rpm for 15 minutes, the kaolin was washed three times with 0.85 per cent $\mathrm{NaCl}$ solution. The washed kaolin was suspended in a volume of eluting solution equal to the original plasma volume. The eluting solution was prepared by dissolving $7 \mathrm{~g}$ of $\mathrm{NaCl}$ in $100 \mathrm{ml}$ of fluid consisting of 1 part imidazole buffer $(\mathrm{pH}$ 7.4) and 4 parts distilled water. The suspension was stirred for 30 minutes at room temperature. The kaolin was then removed by centrifugation at $3,000 \mathrm{rpm}$ for 15 minutes and the eluate was dialyzed in Visking casing against large amounts of distilled water for 18 hours at $4^{\circ} \mathrm{C}$. The inactive precipitate, which formed during dialysis, was removed by centrifugation at $5,000 \mathrm{rpm}$ for 20 minutes and discarded. The SF thus prepared was stable when frozen-stored at $-20^{\circ} \mathrm{C}$. One such preparation lost no activity when stored at this temperature for 6 months. Repeated thawing and freezing should be avoided, however.

Ratnoff, Davie and Mallett (16) recently used PTAdeficient plasma to prepare "a crude fraction, rich in activated Hageman factor and apparently deficient in other known clotting factors," which "corrected the coagulation defect of plasma deficient in Hageman factor, but had no effect upon the clotting time of plasma deficient in PTA. ... The preparation did contain plasminogen." Since there was no PTA-deficient subject available to us, we merely prepared from normal plasma the so-called "surface factor" (14) or "activation product" (15), which we believe is essentially "activated Hageman factor" plus some active PTA. Other known clotting factors are lacking, however. In particular, all traces of thrombin and prothrombin were eliminated. Our SF always has a small content of plasminogen, but if this assayed more than 0.2 caseinolytic units (cas. U) per $\mathrm{ml}$, or if any active plasmin or plasminoplastin was demonstrable, the preparation was considered as unsuitable and discarded. The protein content of our SF preparation averaged $50 \mu \mathrm{g}$ per $\mathrm{ml}$, indicating over 1,000 -fold purification in terms of "activity" per unit weight of protein, compared with the original plasma.

Kaolin-SF was prepared by following the same procedure as for SF, except that the washed kaolin-adsorbate was simply suspended in distilled water, instead of eluted.

This material was also free of other clotting factors, as well as of plasmin or plasminoplastin activity, and its plasminogen content never exceeded 0.4 cas. $U$ per $\mathrm{ml}$.

Bovine plasminogen was prepared by Kline's (17)

\footnotetext{
${ }^{1}$ Cutter Laboratories, Berkeley, Calif.
} 
procedure from bovine plasma Fraction III, and contained 24 cas. $\mathrm{U}$ per $\mathrm{ml}$.

Human plasminogen was prepared similarly, and averaged 80 to 100 cas. $\mathrm{U}$ per $\mathrm{mg} \mathrm{N}$.

Human plasmin was prepared by spontaneous activation of human plasminogen in glycerol (18). After completion of the activation, the glycerol was removed by dialysis against large quantities of $0.01 \mathrm{~N} \mathrm{HCl}$ solution. The preparation was adjusted to $\mathrm{pH} 2$ and heated at $100^{\circ}$ $\mathrm{C}$ for 30 minutes. The heated plasmin solution was allowed to cool to room temperature and then was mixed with an equal volume of $2 \mathrm{M} \mathrm{NaCl}$ solution. The mixture was centrifuged at $3,000 \mathrm{rpm}$ for 30 minutes. The precipitate was dissolved in $0.01 \mathrm{~N} \mathrm{HCl}$ and kept at $-20^{\circ}$ $\mathrm{C}$ until used. Human plasmin, thus prepared, contained about 75 cas. $\mathrm{U}$ per $\mathrm{mg} \mathrm{N}$ (see above), and was devoid of any Hageman-like activity.

Urine plasminoplastin (UP) or "urokinase" was a purified preparation for which we are indebted to Dr. H. O. Singher (Ortho Laboratories).

Streptokinase (SK) was commercial (Lederle's) Varidase. The dry material was readily dissolved in distilled water to give $10,000 \mathrm{U}$ per $\mathrm{ml}$.

$\epsilon$-Aminocaproic acid ( $\epsilon$-aca) was a $4 \mathrm{M}$ stock solution (in distilled water) of a commercially available preparation (Aldrich Chemical Company).

Euglobulin fraction. The plasma (normal human, Hageman-deficient, or chicken) was diluted 20 -fold with distilled water and the $\mathrm{pH}$ adjusted to 5.3 with 1 per cent acetic acid. The suspension was centrifuged at $4^{\circ} \mathrm{C}$ for 15 minutes at $3,000 \mathrm{rpm}$. The sediment was dissolved in a volume of borate buffer ( $\mathrm{pH} 7.6)$ equal to the original plasma volume.

Euglobulin lysis time. Two-tenths $\mathrm{ml}$ of 0.1 per cent bovine fibrinogen was pipetted into a glass tube $(13 \mathrm{~mm}$ $\times 100 \mathrm{~mm}$ ) prewarmed to $37^{\circ} \mathrm{C}$. To this was added 0.2 $\mathrm{ml}$ of the euglobulin preparation (incubated, see below, or otherwise), followed by $0.1 \mathrm{ml}$ of a thrombin-Ca mixture (equal parts of $100 \mathrm{U}$ per $\mathrm{ml}$ thrombin and $0.025 \mathrm{M}$ $\mathrm{CaCl}_{2}$ ). The clot was observed every minute and the time required for complete clot lysis recorded as the euglobulin lysis time.

Plasminoplastin generation test (PGT) (11). Two $\mathrm{ml}$ of intact, citrated, platelet-poor plasma was pipetted into a beaker, diluted with $38 \mathrm{ml}$ of distilled water, adjusted to $\mathrm{pH} 5.3$ with 1 per cent acetic acid, and incubated at $37^{\circ} \mathrm{C}$. At successive time intervals, $4.6-\mathrm{ml}$ samples were removed, centrifuged at $3,000 \mathrm{rpm}$ for 15 minutes at $4^{\circ} \mathrm{C}$, the precipitate (euglobulin) dissolved in $0.23 \mathrm{ml}$ of borate buffer $(\mathrm{pH} \mathrm{7.6)}$ and tested for fibrinolytic activity by the euglobulin lysis time method (see above).

During the incubation there was an increase of the fibrinolytic activity, which was followed for 6 hours. The range and mean of 26 control estimations (from 26 normal persons) are shown in Figure 1. The small group studied did not permit any definite correlation of variations with age, sex, and so forth. Each curve was reproducible and characteristic of the individual, provided that the conditions under which the blood was

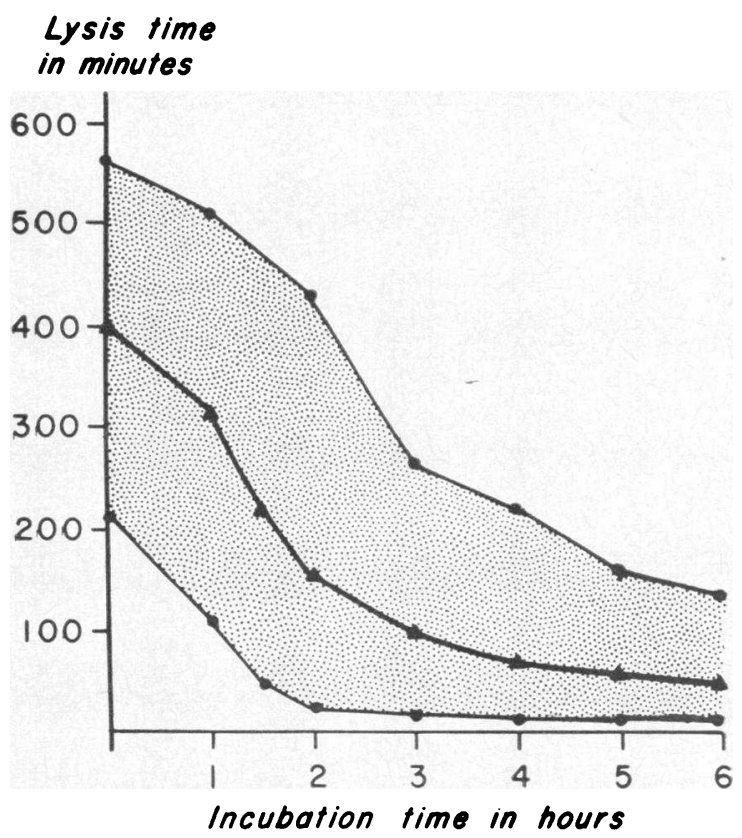

Fig. 1. PGT on NoRMal Plasmas. The average and the range of tests with plasmas from 26 subjects are illustrated.

drawn remained the same. Four separate studies on one individual, shown in Figure 2, indicate only minor variations.

Occasionally the above system was slightly modified by adding agents such as streptokinase, plasmin, SF, kaolin (1 $\mathrm{mg}$ per $\mathrm{ml}$ distilled water) or kaolin-SF. When kaolin ( $1 \mathrm{mg}$ per $\mathrm{ml}$ plasma) was added to a normal PGT system the initial lysis time was shortened and the maximal activity was usually reached in 90 to $120 \mathrm{~min}$ utes (11).

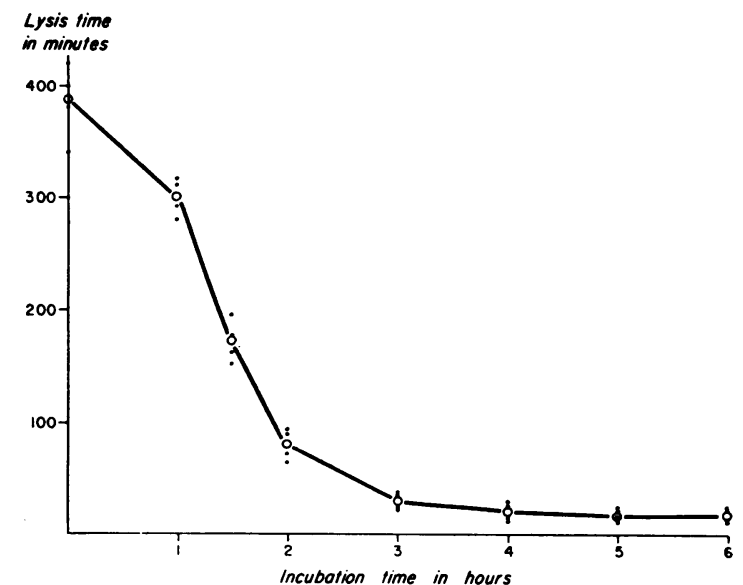

Fig. 2. PGT on NORMAL PLASMa OF ONE SUBJECT. The four points indicate tests on four separate occasions over a 1-month period. The curve represents the average of the four determinations. 
Instead of lysis time, we may express plasminoplastin activity in units. By performing the PGT on Hagemandeficient plasma plus SF and incubating until the shortest lysis time was reached in the euglobulin lysis test, maximally activated euglobulin, that is, maximal plasminoplastin formation was obtained. When the shortest lysis time had been reached, the euglobulin-suspension forming plasminoplastin was centrifuged, the precipitate was redissolved with borate buffer $(\mathrm{pH} 7.6)$ and placed in a water bath of melting ice. Dilutions of this euglobulin were made (with borate buffer $\mathrm{pH} 7.6$ ) and tested by the euglobulin lysis method. A curve relating lysis times and concentration of plasminoplastin was then drawn. One plasminoplastin unit was defined as that amount of plasminoplastin corresponding to 7 minutes' lysis time.

Fibrin plate methods. The well known methods of Astrup and Müllertz (19), as modified by Alkjaersig, Fletcher and Sherry (20), were used.

Proteolytic activity. This activity was determined by a slight modification of the Müllertz (21) caseinolytic assay. The 3 per cent casein solution and the material to be tested were placed in a water bath at $37^{\circ} \mathrm{C}$ until temperature equilibrium was reached (5 minutes), and equal volumes $(2.5 \mathrm{ml})$ were then mixed in a test tube. Two-ml samples, removed immediately after mixing (zero time), and after 60 minutes' incubation at $37^{\circ} \mathrm{C}$, were pipetted into test tubes containing $3 \mathrm{ml}$ of $1.7 \mathrm{M}$ perchloric acid. After 45 minutes (at room temperature) the precipitates were removed by centrifuging and filtering. The absorbance of the supernatants was determined at a wave length of $275 \mathrm{~m} \mu$ on the Beckman DU ultraviolet spectrophotometer, and the increase per 60 minutes was calculated. One caseinolytic unit was arbitrarily taken as that amount of enzyme producing an increase of 200 $\mu \mathrm{g}$ of acid-soluble tyrosine in a medium of 3 per cent casein in 60 minutes at $37^{\circ} \mathrm{C}$.

Plasminogen assay. Human plasminogen was converted to plasmin by an optimal concentration of streptokinase, and the resulting proteolytic activity was measured on casein, as above. Bovine plasminogen was activated by optimal urine plasminoplastin and assayed in the same way.

\section{RESULTS}

\section{Nature of the fibrinolytic factor developed in} the PGT

By performing the PGT (see Methods) on normal plasma plus $1 \mathrm{mg}$ per $\mathrm{ml}$ kaolin (11), and incubating (usually for 2 hours at $37^{\circ} \mathrm{C}$ ) until the shortest lysis time was reached in the euglobulin lysis test, we obtained maximally activated $e u$ globulin- $K$. In the same period, two other preparations of nonactivated (nonincubated) euglobulin were made; i.e., the same plasma (without kaolin) was diluted and acidified, and the euglobulin recovered by centrifugation, redissolved in borate buffer (to original plasma volume), and stored in the refrigerator $\left(4^{\circ} \mathrm{C}\right)$. After the maximal activity of the incubated euglobulin- $\mathrm{K}$ was determined, one of the nonactivated euglobulin preparations was mixed with urine plasminoplastin (UP) in several amounts, selecting that which gave a similar euglobulin lysis time (about $13 \mathrm{~min}$ utes) as the maximally activated euglobulin- $K$; the other was mixed with human plasmin (see Materials), again in an amount yielding a similar lysis time. All three active preparations were then placed in an ice bath to preserve their similar lytic activities.

It is a characteristic of the plasminoplastins to induce more lysis of fibrin when more plasminogen is available (22). On the other hand, the lytic activity of plasmin is not increased by adding plasminogen. In the first experiment, the unheated fibrin plate method was employed. Two rows of plates were prepared: the first with normal bovine fibrin (normal amount of plasminogen), and the second with bovine fibrin fortified with 2.5 cas. $U$ of bovine plasminogen per plate (per $10 \mathrm{ml}$ of fibrin). The plates thus prepared were designated "plasminogen-rich."

Table I shows that euglobulin- $\mathrm{K}$ behaved like a plasminoplastin (euglobulin-UP) and lysed more fibrin in the presence of more plasminogen. In the case of euglobulin-plasmin, there was no significant difference.

The effect of varying amounts of $\epsilon$-aca (22) upon the activity of the three active euglobulins was next investigated. It can be seen from Table II that the inhibition of the fibrinolytic factor of euglobulin- $\mathrm{K}$ by the $\epsilon$-aca was analogous to the inhibition of euglobulin-UP, and was quantitatively different from the inhibition of euglobulin-

TABLE I

Effect of varying plasminogen content upon the lysis of fibrin *

\begin{tabular}{lcc}
\hline & \multicolumn{2}{c}{ Lysed area $\left(\mathrm{mm}^{2}\right)$} \\
\cline { 2 - 3 } Preparation tested & $\begin{array}{c}\text { Normal } \\
\text { fibrin }\end{array}$ & $\begin{array}{c}\text { Plaminogen- } \\
\text { rich fibrin }\end{array}$ \\
\hline Borate buffer & 0 & 0 \\
Euglobulin-K & 206 & 380 \\
Euglobulin-UP & 480 & 670 \\
Euglobulin-plasmin & 365 & 368
\end{tabular}

* Fibrin plate method (unheated fibrin containing plasminogen). 
TABLE II

Inhibition of fibrinolytic activity by є-aminocaproic acid *

\begin{tabular}{lrrrr}
\hline \hline & \multicolumn{4}{c}{ Per cent inhibition by $\epsilon$-aca } \\
\cline { 2 - 5 } \multicolumn{1}{c}{ Preparation tested } & $10^{-4} \mathrm{M}$ & $1^{-3} \mathrm{M}$ & $10^{-2} \mathrm{M}$ & $10^{-1} \mathrm{M}$ \\
\hline Euglobulin-K & 88 & 99 & 100 & 100 \\
Euglobulin-UP & 74 & 80 & 94 & 100 \\
Euglobulin-plasmin & 0 & 56 & 80 & 90 \\
\hline
\end{tabular}

* The euglobulin lysis times (in the absence of $\epsilon$-aca) of the three preparations were adjusted to the same level and considered as $100 \%$ activity. The results illustrate the inhibitory effect of $\epsilon$-aca upon the three euglobulins.

plasmin. This fact again tentatively suggests a similar nature of the fibrinolytic factors in euglobulin- $\mathrm{K}$ and euglobulin-UP.

The fate of each of the above euglobulins after acid-heat treatment was also investigated. It is known that purified preparations of plasmin are stable at low $\mathrm{pH}$ (below 4) and that they may be

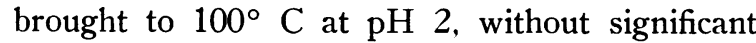
loss of activity (23). Urine plasminoplastin, while stable at temperatures up to $50^{\circ} \mathrm{C}$, loses its stability and is denatured at higher temperatures. Little is known concerning the heat stability of plasma plasminoplastin. However, it is considered more labile than tissue or urine plasminoplastins, at least in the crude materials so far available.

In the present preliminary experiment the lability of these factors should not be compared with that of the purified preparations, mainly because the presence of gross impurities in the euglobulins may affect their degree of stability.

All three euglobulins were adjusted to $\mathrm{pH} \mathrm{2,}$ heated for 30 minutes at $100^{\circ} \mathrm{C}$, brought back to neutrality, and tested for residual activity by the euglobulin lysis time method. It can be seen (Table III) that the percentage loss in activity differed in the three cases. Only in the euglobulin- $\mathrm{K}$ was there total (100 per cent) loss.

TABLE III

Loss of fibrinolytic activity by acid-heat treatment *

\begin{tabular}{ccc}
\hline \multicolumn{3}{c}{ Per cent loss of activity } \\
\cline { 2 - 4 } Euglobulin-K & Euglobulin-UP & $\begin{array}{c}\text { Euglobulin- } \\
\text { plasmin }\end{array}$ \\
\hline 100 & 84 & 78 \\
\hline
\end{tabular}

* All three euglobulins were adjusted to $\mathrm{pH} 2$, heated for 30 minutes at $100^{\circ} \mathrm{C}$, brought back to neutrality, and tested.
2. Role of $S F$ (dependent on Hageman factor) in the generation of the endogenous plasminoplastin

It has been shown (11) that the generation of endogenous plasminoplastin in Hageman-deficient plasma is defective and that Hageman factor, while not identical with plasminogen and proplasminoplastin, does participate in the reaction(s) of plasminoplastin formation. The following experiment confirms these facts.

In one beaker (I), $2 \mathrm{ml}$ of Hageman-deficient plasma was mixed with $2 \mathrm{ml}$ of a kaolin-SF preparation (see Materials), then diluted with $36 \mathrm{ml}$ of distilled water, and the $\mathrm{pH}$ adjusted to 5.3 with 1 per cent acetic acid. In a second beaker (II), $2 \mathrm{ml}$ of the same kaolin-SF was diluted 20 -fold with distilled water and the $\mathrm{pH}$ adjusted to 5.3 as above. In a third beaker (III), $2 \mathrm{ml}$ of Hagemandeficient plasma was treated similarly. All three test systems were incubated at $37^{\circ} \mathrm{C}$ for 6 hours. At intervals, samples from the first test system were processed (see Methods) for the estimation of the euglobulin lysis time. Simultaneously and at the same incubation times, equal volumes of the second and third systems (II and III) were mixed in a tube, centrifuged, and the precipitate reconstituted with a volume of borate buffer equal to the original plasma volume (of the third sys-

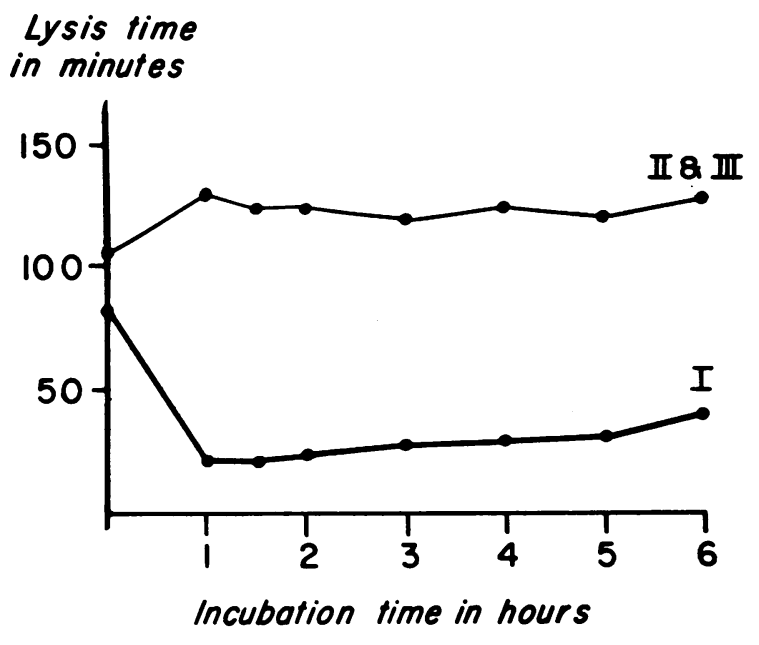

Fig. 3. PGT on Hageman-deficient plasma. Curve I, Hageman-deficient plasma preincubated with SF; curve II and III, Hageman-deficient plasma and SF preincubated separately and only mixed before centrifugation. 


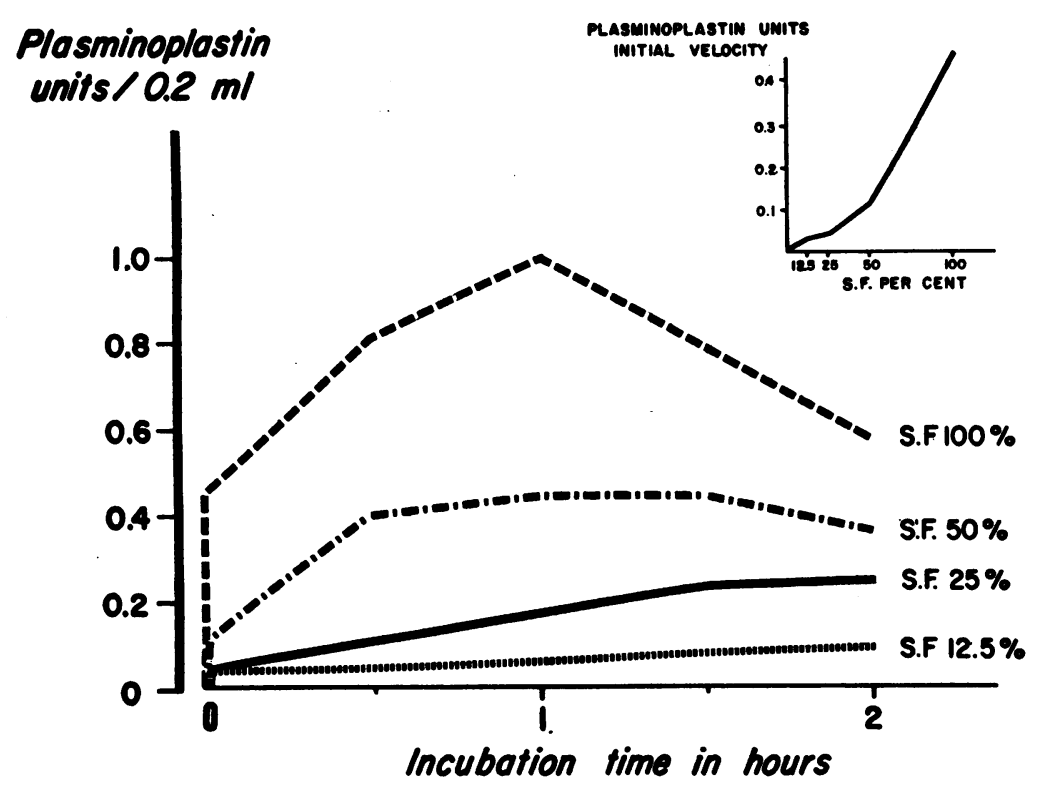

Fig. 4. Generation of endogenous plasminoplastin in Hageman-deFICIENT PLASMA WITH SF. The ordinate gives units of plasminoplastin formed. The abscissa gives incubation periods. The ordinate on the inset figure represents initial reaction velocity. See text for other details.

tem), for the estimation of the euglobulin lysis time.

It can be seen from Figure 3, curve I, that preincubation of Hageman-deficient plasma and kaolin-SF in the same beaker resulted in generation of endogenous plasminoplastin. On the other hand, when Hageman-deficient plasma and kaolinSF were preincubated separately (curve II + III) and mixed only at the time of centrifugation, there was no increase in fibrinolytic activity. This suggests that neither Hageman-deficient plasma nor kaolin-SF, alone, is a complete and adequate system for the formation of the endogenous plasminoplastin, whereas, when preincubated together, each contributes to the formation of this endogenous plasminoplastin.

\section{Evidence that SF (Hageman-dependent) acts as catalyst in the generation of the endogenous plasminoplastin}

Figure 4 shows a PGT study (the values are given in units) on the generation of the endogenous plasminoplastin by Hageman-deficient plasma with varying additions of SF. The relationship (inset figure) observed between SF concentration and initial reaction velocity may suggest an enzymatic or catalytic action of SF. However, the present evidence is no more than suggestive and does not permit an analysis of kinetics. More work will be needed for the final answer.

\section{Role of surface}

It has been shown (11) that, in the PGT of Hageman-deficient plasma, kaolin causes a significant shortening of the initial euglobulin lysis time, but this does not progress. The following experiment was undertaken to clarify the role of "surface" in the generation of endogenous plasminoplastin.

It was shown that when the PGT was performed with Hageman-deficient plasma and the systems were incubated in siliconized beakers, a weak SF preparation, which did not greatly affect the initial euglobulin lysis time, did, however, produce a continuously progressive increase of plasminoplastin (Figure 5, curve 3). While the same weak SF preparation in the presence of kaolin $(1 \mathrm{mg}$ per $\mathrm{ml}$ ) (Figure 5, curve 4) did not affect the initial euglobulin lysis time obtained with kaolin alone (Figure 5, curve 2), it nevertheless caused a progressive increase of plasminoplastin in the 


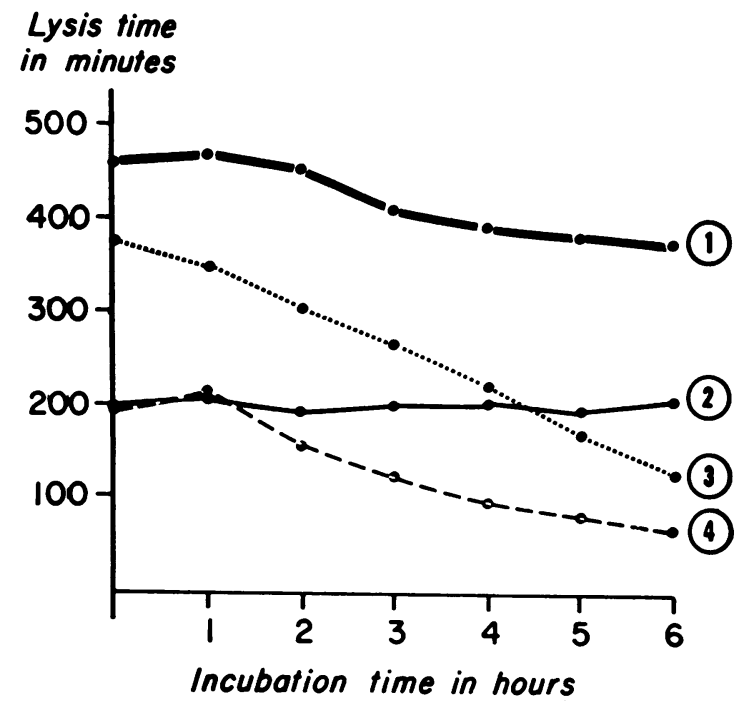

Fig. 5. EfFects of Kaolin (curve 2), SF (curve 3), and Kaolin plus SF (Curve 4) on PGT of HagemanDEFICIENT PLASMa. The control (curve 1) is a PGT of Hageman-deficient plasma without any additive.

earlier stages. This leveled off, however, at essentially the same end point as was reached, more slowly, by SF alone (Figure 5 , curve 3 ). It can also be seen from the same Figure 5 (curve 1) that the control-namely, Hageman-deficient plasma without any additive-did not increase its plasminoplastin activity over the 6 hours of incubation.

The present experiment tentatively suggests that the role of surface, itself, in the generation of endogenous plasminoplastin is limited. When SF (Hageman-dependent) is preformed, the surface does not add significantly to the over-all rate of activation. Hence, it would appear that in normal plasma the surface contributes to the formation of endogenous plasminoplastin by participating in the activation of Hageman factor.

\section{Site of action of SF (Hageman-dependent)}

Streptokinase is known to act on a precursor (proplasminoplastin) in the fibrinolytic system to form a plasminoplastin. Without raising questions regarding the nature or exact mode(s) of action, a comparative study was made of streptokinase, SF, and plasmin as "activators" in the PGT system with $a$ ) normal plasma, $b$ ) Hageman-deficient plasma, and $c$ ) chicken plasma.

a) Normal plasma test systems (Figure 6a). Test 1 was a control run without any additive; test 2 was with $1 \mathrm{mg}$ kaolin per $\mathrm{ml}$; test 3 was with streptokinase (SK); and test 4 was with human plasmin. The amounts of SK and plasmin were adjusted so that both gave approximately the same euglobulin lysis times, at zero incubation, as in the kaolin experiment. It was found that, under the conditions employed in these experiments, 2 cas. $\mathrm{U}$ plasmin per $\mathrm{ml}, 0.2 \mathrm{U}$ streptokinase per $\mathrm{ml}$, and $1 \mathrm{mg}$ kaolin per $\mathrm{ml}$ had the same effect on the initial lysis time (zero incubation).

It can be seen from Figure 6a that test 2 with kaolin, and test 3 with SK, gave essentially similar curves. On the other hand, test 4 with plasmin, despite the similar initial value, progressed much more slowly. The control, test 1 , was poor initially, but gradually approached the same order of activity as that in the other systems after about 4 hours.

b) Hageman-deficient plasma test systems (Figure $6 b$ ). Tests 2, 3, and 4 were run in a manner analogous to the corresponding tests in Figure 6a. No control was necessary, since plasminoplastin fails to develop in the absence of Hageman factor (11) (Figure 5, curve 1). Instead, test 5 was run with kaolin-SF (see Ma-
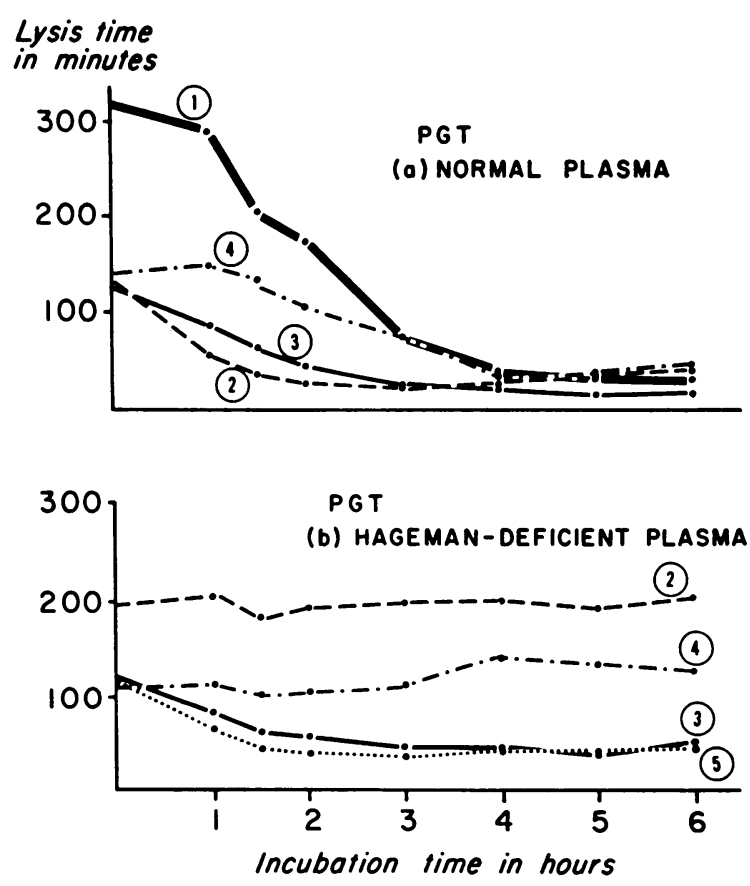

Fig. 6. EFFECTS OF DIFFERENT ACTIVATOR AGENTS ON PGT of (a) NORMAL PLASMa AND (b) HAgeMan-DEFICIENT Plasma. See text for other details. 
terials) to restore SF and the necessary surface, thereby normalizing the initial euglobulin lysis time. Figure $6 \mathrm{~b}$, test 2 , shows the usual failure of kaolin to develop plasminoplastin activity in the Hageman-deficient test system (11). Test 3 with SK, clearly developed plasminoplastin activity. Test 5 with kaolin-SF, behaved like test 3 . On the other hand, test 4 with plasmin, showed no increase in plasminoplastin activity.

The similarity in both systems (Figure 6, a and b) between SK and SF (plus surface) at least suggests that both work by forming a plasminoplastin. Active plasmin is significantly different in this regard and fails to develop additional fibrinolytic activity (i.e., plasminoplastin) in the Hageman-deficient system.

In the normal plasma system (Figure 6a, test 2) kaolin apparently works by surface activation of the Hageman factor, since there is no progression of the initial fibrinolytic activity when kaolin is added to the Hageman-deficient plasma system (Figure 6b, test 2).

Table IV presents data obtained by testing initial and 5-hour incubates of the previous experiment (Figure 6, $\mathrm{a}$ and $\mathrm{b}$; tests 3 and 4 ) by the fibrin plate method. It is evident that in the absence of the Hageman factor (Hageman-deficient systems) only the system with SK showed increased plasminoplastin activity (unheated fibrin) in the 5-hour sample, while that with plasmin not only failed to develop more activity but lost most of that possessed at zero time. It can also be seen that almost identical results were obtained with the normal euglobulin systems.

c) Chicken plasma test systems (Figure 7). In preliminary experiments, not included in this communication, it was shown that the chicken

TABLE IV

Effect of streptokinase and human plasmin on the generation of endogenous plasminoplastin*

\begin{tabular}{|c|c|c|c|c|}
\hline \multirow{3}{*}{$\begin{array}{l}\text { Systems preincubated at } \\
\qquad 37^{\circ} \mathrm{C}\end{array}$} & \multicolumn{4}{|c|}{ Lysed area $\left(\mathrm{mm}^{2}\right)$} \\
\hline & \multicolumn{2}{|c|}{$\begin{array}{c}\text { Unheated } \\
\text { fibrin }\end{array}$} & \multicolumn{2}{|c|}{$\begin{array}{c}\text { Heated } \\
\text { fibrin }\end{array}$} \\
\hline & 0 & $5 \mathrm{hrs}$ & 0 & $5 \mathrm{hrs}$ \\
\hline $\begin{array}{l}\text { Normal euglobulin }+\mathrm{SK} \\
\text { Normal euglobulin }+ \text { plasmin } \\
\text { Hag-def. euglobulin }+\mathrm{SK} \\
\text { Hag-def. euglobulin + plasmin }\end{array}$ & $\begin{array}{l}221 \\
144 \\
284 \\
121\end{array}$ & $\begin{array}{r}382 \\
253 \\
371 \\
63\end{array}$ & $\begin{array}{l}100 \\
100 \\
118 \\
111\end{array}$ & $\begin{array}{r}100 \\
85 \\
100 \\
<30\end{array}$ \\
\hline
\end{tabular}

* Fibrin plate method. The preparations were samples obtained from the incubates shown in Figure 6, $a$ and $b$, tests 3 and 4 . fibrinolytic system, while readily activated with urine plasminoplastin, remained completely inactive in the presence of streptokinase. It was therefore concluded that chicken plasma has adequate plasminogen, but is deficient in proplasminoplastin. On the basis of these data, and taking into consideration the additional fact that chicken plasma is Hageman-deficient (24) (also confirmed in our laboratory), we performed the following PGT experiment.

Test 1 was a control without any additive; test 2 was with $1 \mathrm{mg}$ kaolin per $\mathrm{ml}$; test 3 was with 1 $\mathrm{ml}$ kaolin-SF per $\mathrm{ml}$. It can be seen (Figure 7) that chicken plasma without additive (test 1 ) or with kaolin (test 2) behaved similarly, failing to develop any plasminoplastin activity. These results were anticipated, since chicken plasma is Hageman-deficient. In test 3 it can be seen that despite the addition of SF, the chicken test system did not develop any plasminoplastin activity. The slightly shorter lysis times obtained throughout this test might be attributed to insignificant traces of human plasminogen (and proplasminoplastin) in our kaolin-SF preparation (see Materials). It can be concluded that, since kaolin-SF failed to develop endogenous plasminoplastin in

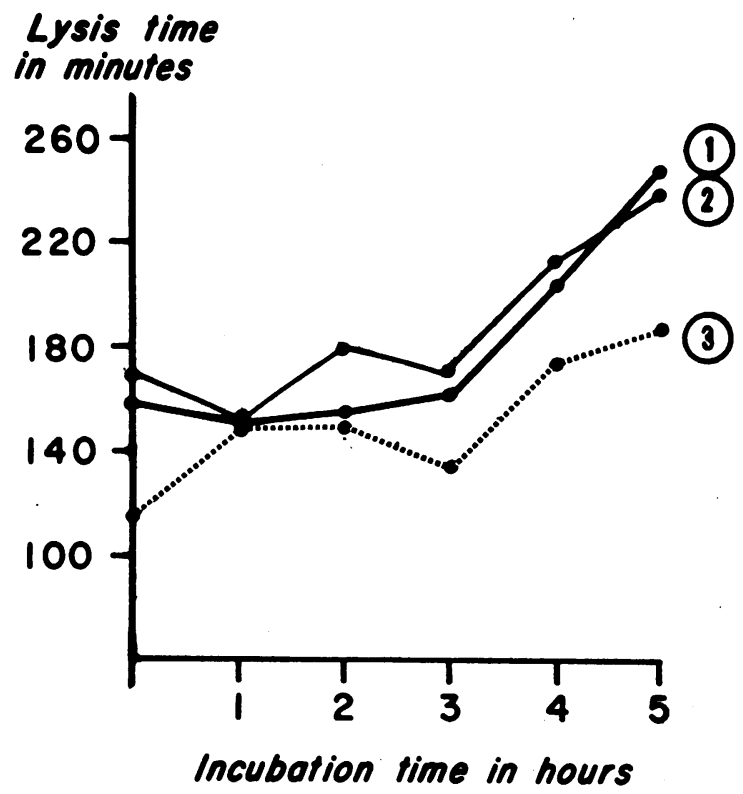

Fig. 7. PGT on chicken Plasma. Curve 1 is a control test without any additive; curve 2 is a test with kaolin ( $1 \mathrm{mg}$ per $\mathrm{ml}$ ); and curve 3 is a test with kaolin$\mathrm{SF}$ (1 $\mathrm{ml}$ per $\mathrm{ml})$. 
a system which is deficient in proplasminoplastin, it only acts when proplasminoplastin is present. Hence, SF is only efficient for the generation of endogenous plasminoplastin when its precursor (the proplasminoplastin) is available.

\section{DISCUSSION}

The present study confirms and extends previous observations on a role of Hageman factor in the activation of the fibrinolytic system $(10,11$, 25). It also characterizes as a plasminoplastin the agent which is developed in the incubation phase of the plasminoplastin generation test (PGT). The elucidation of the role of Hageman factor in the fibrinolytic system can therefore be explored in terms of the formation of "endogenous plasminoplastin."

The severe defect in the generation of endogenous plasminoplastin in Hageman-deficient plasma indicates a major role for some "activator" factor lacking in such plasma. Our SF preparation (dependent upon activation of the Hageman factor) corrects the above defect when it is incubated with the Hageman-deficient plasma in the PGT.

In a previous study (11) it was found that Hageman factor is not identical with plasminogen or proplasminoplastin. It was also established that Hageman-deficient plasma has normal amounts of these factors. There is substantial evidence that the failure of the Hageman-deficient plasma to develop plasminoplastin activity is due to the absence of Hageman factor. After restoration of the "Hageman clotting factor" defect by addition of SF, the fibrinolytic activity of Hageman-deficient system is also normalized, specifically the generation of endogenous plasminoplastin.

Our SF preparation is relatively crude and does not permit the exact identification of the "activator" agent. It could be the entire "active Hageman-PTA complex" or "active Hageman" itself (which will be tested when the opportunity to prepare PTA-free "active Hageman" occurs). It does not depend upon PTA alone, since this factor is known to be present in the Hageman-deficient system. It could conceivably depend upon some as yet unidentified agent, coincidentally absent from Hageman-deficient plasma and present in our SF preparation. Future work will be needed for the final answer.
A minor role of surface, interpreted from its action on Hageman-deficient plasma, with and without added SF, appears to be limited to some initial activation of the fibrinolytic system which does not progress unless SF (Hageman-dependent) is added. Hence, in normal plasma, the surface mainly contributes to the activation of the fibrinolytic system by activating Hageman factor.

The observation that Hageman factor is necessary for the formation of the endogenous plasminoplastin raised the question of its site of action. According to our data, the generation of the endogenous plasminoplastin is only brought about when adequate amounts of proplasminoplastin and Hageman factor (or SF) are present. Chicken plasma, which is deficient in both factors, does not form endogenous plasminoplastin. It still does not do so even after restoration of Hageman factor in the form of kaolin-SF. Presumably, the active Hageman factor brings about the formation of plasminoplastin by acting on its precursor (the proplasminoplastin). In this respect, Hageman factor seems to have the same site, but not necessarily the same mode, of action as streptokinase, which is the "type" of a lysokinase.

The suggestion (Figure 4) as to a catalytic or enzymatic mode of action of SF (Hageman-dependent) upon proplasminoplastin, is tentatively based upon the measurement of the initial velocity. It was shown that the progress curves obtained with four different amounts of SF are of the general form of most enzyme reactions. By plotting the initial velocity against the amount of SF. a curve was obtained, which was slightly deviant from the linear curve obtained in pure enzymesubstrate systems. It is known that such deviant curves are obtained when small amounts of impurities are present in the substrate. Hardisty and Margolis (26) originally suggested that active Hageman factor acts catalytically to convert PTA into an "active" form. The supporting evidence came from Becker's (27) demonstration that diisopropyl fluorophosphate inhibits the coagulant properties of active Hageman factor. Similar observations were made by Ratnoff and associates (16). Pending final proof that Hageman factor has two natural substrates-namely, proplasminoplastin and PTA - the apparent parallelism may be emphasized. 
Being aware from our previous work (14) that plasmin preparations are usually contaminated with a "Hageman-like" factor, we prepared a plasmin free from such activity (see Materials). With this preparation, we were able to show convincingly the inability of plasmin to activate the proplasminoplastin in Hageman-deficient plasma, even when it was used in a concentration of 2 cas. $\mathrm{U}$ per $\mathrm{ml}$, which corresponds to almost half the potential plasmin yield of the plasma plasminogen (Figure $6 \mathrm{~b}$, test 4 ). In the corresponding experiment on normal plasma (Figure 6a, test 4), the reaction takes place in the presence of Hageman factor, and thus any additional action of plasmin could not be shown. That plasmin is not needed for plasminoplastin generation indicates that this enzyme is unrelated to the factors which interact to form endogenous plasminoplastin.

The present evidence, which clearly suggests that active Hageman factor participates in endogenous plasminoplastin formation, strongly indicates that Hageman factor may be the precursor of natural "plasma lysokinase" responsible for the activation of proplasminoplastin and the increase of the amount of endogenous plasminoplastin, which is considered to be the main thrombolytic agent in vivo (23). It is implicit in this new hypothesis that thrombolytic activity in vivo, a phenomenon reflecting the concentration of the plasminoplastin in the circulation, depends on the level of active Hageman factor. Figure 8 is a schematic representation of this hypothesis. As

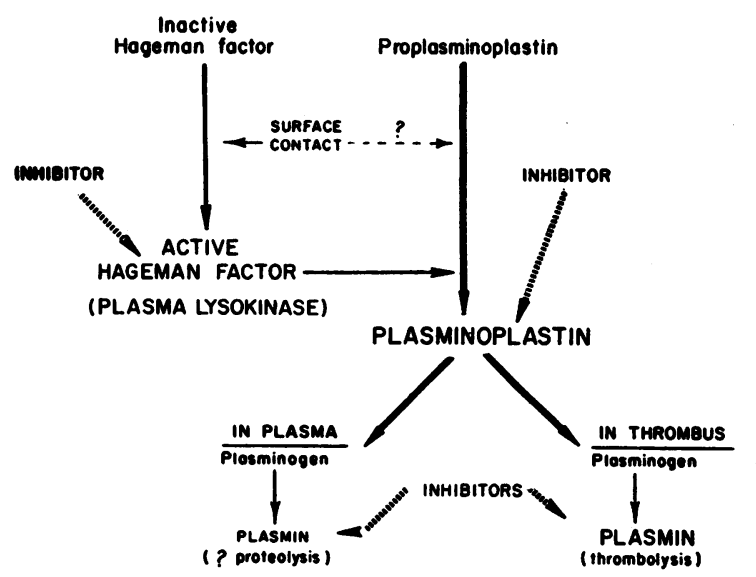

Fig. 8. Tentative scheme showing the possible ROLE OF HAGEMAN FACTOR IN THE THROMBOLYTIC PROCESS. can be seen, endogenous plasminoplastin, after its formation, may convert both plasma plasminogen and plasminogen trapped in a thrombus to plasmin. However, plasma plasmin has an entirely different fate from plasmin in the thrombus. In the plasma, inhibitory substances rapidly inhibit whatever plasmin is formed. Consequently, under these conditions, plasma plasmin is seldom available for effective thrombolysis. On the other hand, plasmin formed within a thrombus is relatively uninhibited in its action, and thus brings about the dissolution of the fibrin without causing generalized proteolysis. Hence, the concentration of circulating plasminoplastin, rather than the amount of plasma plasmin, determines the rate of resolution of fibrin-containing thrombi.

\section{SUM MARY}

A simple and sensitive method, the plasminoplastin generation test (PGT) has been described, which involves determination of the euglobulin lysis time of samples taken from diluted ( 20 -fold with distilled water) plasma, adjusted to $\mathrm{pH} 5.3$, and incubated at $37^{\circ} \mathrm{C}$. It was found that the fibrinolytic factor, which increases during the incubation phase of the PGT, is a plasminoplastin (activator).

The results indicate that the generation of normal endogenous (or plasma) plasminoplastin depends on the presence of adequate amounts of "proplasminoplastin" (proactivator) and Hageman factor. They also suggest that activated Hageman factor brings about the generation of the endogenous plasminoplastin by an enzymatic process.

These studies are in agreement with the hypothesis that plasmin is unrelated to the generation of endogenous plasminoplastin and to the factors which interact to form it.

A tentative scheme is proposed relating the new hypothesis involving Hageman factor to the main steps in the thrombolytic process. It includes the current concept that thrombolysis typically occurs without significant increase in plasma (circulating) plasmin.

\section{ACKNOWLEDGMENT}

We record with pleasure our indebtedness to Miss Eve C. Sandlin for technical assistance. 


\section{REFERENCES}

1. Astrup, T. Fibrinolysis in the organism. Blood 1956, 11, 781.

2. Goldhaber, P., Cornman, I., and Ormsbee, R. A. Experimental alteration of the ability of tumor cells to lyse plasma clots in vitro. Proc. Soc. exp. Biol. (N. Y.) 1947, 66, 590.

3. Astrup, T., and Sterndorff, I. Fibrinolysokinase activity in animal and human tissue. Acta physiol. scand. 1956, 37, 40.

4. Astrup, T., and Permin, P. M. Fibrinolysis in the animal organism. Nature (Lond.) 1947, 159, 681.

5. Kwaan, H. C., Lo, R., and McFadzean, A. J. S. Production of plasma fibrinolytic activity within veins. Clin. Sci. 1957, 16, 241.

6. Kwaan, H. C., Lo, R., and McFadzean, A. J. S. Lysis of thrombi experimentally produced within veins. Brit. J. Haemat. 1958, 4, 51.

7. Kwaan, H. C., Lo, R., and McFadzean, A. J. S. Inhibition of plasma fibrinolytic activity by exercised ischaemic muscles. Clin. Sci. 1958, 17, 361.

8. Müllertz, S. Activation of plasminogen. Ann. N. Y. Acad. Sci. 1957, 68, 38.

9. Lewis, J. H., and Ferguson, J. H. Studies on a proteolytic enzyme system of the blood. IV. Activation of profibrinolysin by serum fibrinolysokinase. Proc. Soc. exp. Biol. (N. Y.) 1951, 78, 184.

10. Iatridis, S. G. The effects of surface on plasminogen activation. Fed. Proc. 1961, 20, 58.

11. Iatridis, S. G., and Ferguson, J. H. Effects of surface and Hageman factor on the endogenous or spontaneous activation of the fibrinolytic system. Thromb. Diath. haemor. 1961, 6, 411.

12. Ferguson, J. H., Wilson, E. G., Iatridis, S. G., Rierson, H. A., and Johnston, B. R. Enzymes and blood clotting. I. Trypsin as an accessory factor. J. clin. Invest. 1960, 39, 1942.

13. Johnston, C. L., Jr., Ferguson, J. H., and O'Hanlon, F. A. Surface activation of plasma clotting: A function of Hageman Factor. Proc. Soc. exp. Biol. (N. Y.) 1958, 99, 197.

14. Iatridis, S. G., Wilson, E. G., Ferguson, J. H., and Rierson, H. A. Blood clotting activities of thrombolytic agents with special reference to a Hage- man-like effect. Thromb. Diath. haemor. 1960, 5, 50.

15. Waaler, B. A. Contact activation in the intrinsic blood clotting system. Scand. J. clin. Lab. Invest. 1959, 11, suppl. 37.

16. Ratnoff, O. D., Davie, E. W., and Mallett, D. L. Studies on the action of Hageman factor: Evidence that activated Hageman factor in turn activates plasma thromboplastin antecedent. J. clin. Invest. 1961, 40, 803.

17. Kline, D. L. The purification and crystallization of plasminogen (profibrinolysin). J. biol. Chem. 1953, 204, 949.

18. Alkjaersig, N., Fletcher, A. P., and Sherry, S. The activation of human plasminogen. I. Spontaneous activation in glycerol. J. biol. Chem. 1958, 233, 81.

19. Astrup, T., and Müllertz, S. The fibrin plate method for estimating fibrinolytic activity. Arch. Biochem. 1952, 40, 346.

20. Alkjaersig, N., Fletcher, A. P., and Sherry, S. $\epsilon$-Aminocaproic acid: An inhibitor of plasminogen activation. J. biol. Chem. 1959, 234, 832.

21. Müllertz, S. Formation and properties of the activator of plasminogen and of human and bovine plasmin. Biochem. J. 1955, 61, 424.

22. Sawyer, W. D., Fletcher, A. P., Alkjaersig, N., and Sherry, S. Studies on the thrombolytic activity of human plasma. J. clin. Invest. 1960, 39, 426.

23. Sherry, S., Fletcher, A. P., and Alkjaersig, N. Fibrinolysis and fibrinolytic activity in man. Physiol. Rev. 1959, 39, 343.

24. Soulier, J. P., Wartelle, O., and Ménaché, D. Caractères différentiels des facteurs Hageman et PTA. Rôle du contact dans la phase initiale de la coagulation. Rev. franç. Et. clin. biol. 1958, 3, 263.

25. Niewiarowski, S., and Prou-Wartelle, O. Rôle du facteur contact (facteur Hageman) dans la fibrinolyse. Thromb. Diath. haemor. 1959, 3, 593.

26. Hardisty, R. M., and Margolis, J. The role of Hageman factor in the initiation of blood coagulation. Brit. J. Haemat. 1959, 5, 203.

27. Becker, E. L. Inactivation of Hageman factor by diisopropylfluorophosphate (DFP). J. Lab. clin. Med. 1960, 56, 136. 